\title{
Trabalho em equipe na perspectiva da gerência de serviços de saúde: instrumentos para a construção da prática interprofissional
}

\author{
I ${ }^{1}$ Marina Peduzzi, ${ }^{2}$ Brígida Gimenez Carvalho, ${ }^{3}$ Edir Nei Teixeira Mandú, \\ ${ }^{4}$ Geisa Colebrusco de Souza, 5 Jaqueline Alcântara Marcelino da Silva I
}

Resumo: Estuda-se a contribuição da ação gerencial para a promoção da prática interprofissional. Trata-se de pesquisa qualitativa, realizada em 21 serviços públicos de saúde de uma região de São Paulo, por meio de entrevista semiestruturada com 21 gerentes (diretores) e utiliza-se a técnica de análise temática. Como resultado, para promover o trabalho em equipe, os gerentes lançam mão dos instrumentos: comunicação, construção do compromisso das equipes e dos trabalhadores com o projeto institucional, estímulo à autonomia das equipes, definição de responsabilidades e accountability, promoção de mudança da cultura institucional e supervisão externa. Conclui-se que a comunicação e demais ferramentas quando aplicadas à promoção do trabalho em equipe estão orientadas ao trabalho, isto é, à atenção eficaz e eficiente às necessidades de saúde dos usuários.

> Palavras-chave: equipe de assistência ao paciente; gerência; trabalho.

\author{
1 Professora associada (livre- \\ docente) do Departamento \\ de Orientação Profissional da \\ EEUSP. Endereço eletrônico: \\ marinape@usp.br \\ 2 Professora assistente do \\ Departamento de Saúde \\ Coletiva da UEL; doutoranda do \\ Programa de Pós-Graduação em \\ Gerenciamento em Enfermagem \\ da EEUSP. Endereço eletrônico: \\ brigidagimenez@gmail.com

\begin{abstract}
3 Professora associada da Faculdade de Enfermagem da UFMT. Endereço eletrônico: enmandu@terra.com.br

4 Enfermeira especialista em Laboratório do Departamento de Orientação Profissional da EEUSP; mestre em Ciências pelo Programa de Pós-Graduação em Gerenciamento em Enfermagem da EEUSP. Endereço eletrônico: geisacole@usp.br

5 Enfermeira especialista em Laboratório do Departamento de Orientação Profissional da EEUSP; doutoranda do Programa de Pós-Graduação em Gerenciamento em Enfermagem da EEUSP. Endereço eletrônico: jaqueline.alc@gmail.com
\end{abstract}




\section{Introdução}

O contexto de prestação de serviços de saúde das últimas décadas ampliou o reconhecimento da necessidade da prática interprofissional para aumentar a eficiência e eficácia da atenção à saúde. Isso é estimulado por vários aspectos interligados, como: mudanças no perfil demográfico e epidemiológico da população, que resultam em envelhecimento, aumento das doenças crônicodegenerativas e mortes por causas externas (WIECHA; POLLARD, 2004), incorporação tecnológica e custos crescentes do setor (MILLER; FREEMAN, ROSS, 2001; RETCHIN, 2008), intensificação do debate sobre a complexidade das necessidades de saúde e da abordagem integral na atenção à saúde (McCALLIN, 2001; PEDUZZI, 2001, 2007a; FORTUNA et al., 2005) e extensa crítica ao modelo gerencial hegemônico taylorista/fordista em saúde (CAMPOS; DOMITTI, 2007; CAMPOS, 2000).

Considerando esse desafio, analisa-se o trabalho em equipe da perspectiva de gerentes de serviços de saúde, visto que a literatura sobre o tema aponta a importância da ação gerencial à promoção da prática interprofissional (MILLER; FREEMAN; ROSS, 2001; McCALLIN, 2001; CAMPOS, DOMITTI, 2007; CAMPOS, 2000; FORTUNA, 1999). Essa literatura destaca a atuação da gerência, sobretudo ao compartilhar com clareza o projeto institucional, particularmente a finalidade do processo de trabalho e os objetivos do serviço, buscando assegurar o compromisso das equipes com tal projeto e com as necessidades de saúde dos usuários e da população. Assim, espera-se que a equipe de saúde tenha adesão crítica ao projeto institucional, isto é, que se comprometa e envolva com ele de forma dialogada, em interação não apenas com os gerentes, mas especialmente com usuários (indivíduos, famílias e população dos territórios de saúde).

Campos (2000) discute a ordem organizacional tradicional da atenção à saúde e parte do pressuposto de que a subjetividade dos trabalhadores das equipes também é influenciada pela estrutura organizacional e organização dos processos de trabalho. Nesse sentido, caracteriza o que denomina contexto socioeconômico e político do trabalho em equipe, em que destaca o estilo de governo, a estrutura organizacional, as relaçôes de poder e o modelo técnico-assistencial. Segundo o autor, a ordem tradicional dos serviços reforça o isolamento profissional, produz fragmentação e dificulta o trabalho em equipe, pois nela os profissionais, pares ou de diferentes áreas, somam procedimentos, lado a lado, supondo que cumprindo 
sua parte garantirão a qualidade do todo da atenção à saúde. Como alternativa, propõe as equipes de referência e apoio especializado matricial como um arranjo à gestão do trabalho para assegurar maior eficácia e eficiência à atenção à saúde, investir na construção da autonomia dos usuários e reforçar o poder de gestão de equipes, ou seja, deslocar o poder das profissões e corporações de especialistas para o poder da gestão de equipes (CAMPOS; DOMITTI, 2007).

Também problematizando a ordem organizacional tradicional, Fortuna (1999) analisa a potência da gerência do serviço em se constituir como desencadeador dos processos de revisão do trabalho, favorecendo a reconfiguração das equipes no sentido de maior integração e compartilhamento do poder. Para a autora, o trabalho em equipe requer a revisão da rede de micropoderes e das materializações daquilo que está instituído, de modo a revelar o explícito e o implícito dos papéis assumidos e adjudicados e dos objetivos em disputa no serviço.

Da ótica da gerência local de serviços, o trabalho em equipe é tema relacionado à organização do trabalho e coloca em questão as ferramentas que permitem sua construção e sustentação ao longo do tempo. Assim, apresentam-se resultados de pesquisa com o objetivo de analisar os instrumentos de que se valem os gerentes para promover o trabalho em equipe interprofissional.

$\mathrm{O}$ estudo justifica-se pela necessidade de ampliar o conhecimento e as possíveis intervenções de gerentes e gestores do setor junto às equipes de saúde, na perspectiva da prática interprofissional e interdisciplinar, para fortalecimento e consolidação da integralidade da saúde (MATTOS, 2004; PINHEIRO; BARROS; MATTOS, 2007), principal ancoragem da proposta de trabalho em equipe interprofissional em substituição ao trabalho individualizado por profissional (PEDUZZI, 2007b).

O trabalho em equipe caracteriza-se pela relação recíproca, de dupla mão, entre trabalho e interação, visto que a comunicação entre profissionais faz parte do exercício cotidiano de trabalho e lhes permite articular as inúmeras ações executadas na equipe, no serviço e na rede de atenção (PEDUZZI, 2001, 2007a, 2007b). A literatura nacional e internacional sobre o tema converge ao reconhecer a comunicação entre os profissionais como sua condição sine qua non (WIECHA; POLLARD, 2004; McCALLIN, 2001; PEDUZZI, 2001, 2007a, 2000b; FORTUNA et al., 2005). Assim, as interpretações que fundamentam esta pesquisa sustentam-se em uma abordagem histórico-social do processo de 
trabalho em saúde e na teoria do agir comunicativo (PEDUZZI, 2001, 2007a, 2007b; SCHRAIBER et al., 1999; AYRES, 2009).

\section{Referencial teórico}

No campo da saúde/enfermagem, as categorias trabalho e processo de trabalho em saúde foram desenvolvidas por pesquisadores como Ricardo Bruno Mendes Gonçalves, Lilia Blima Schraiber, Emerson Elias Merhy, Maria Cecília Puntel de Almeida, Denise Pires, dentre outros, a partir de meados dos anos 1970, com base em contribuições clássicas de Karl Marx.

O processo de trabalho em saúde é constituído pelos objetos de trabalho, que resultam de recortes técnico-sociais na leitura das necessidades de saúde, sobre os quais incidem as ações dos diferentes profissionais, mediadas por instrumentos materiais e não materiais. $\mathrm{O}$ mesmo integra os processos específicos de cada área que compõe o campo da saúde, pois cada uma constitui, histórica e socialmente, objetos de intervenção, instrumentos - em particular os saberes -, agentes e finalidades próprias.

A partir da segunda metade dos anos 1990, observa-se a incorporação de outras vertentes teóricas ao referencial, na Saúde Coletiva (AYRES, 2002) e Enfermagem (ALMEIDA; MISHIMA; PEDUZZI, 1999), que propiciaram o aprofundamento da dimensão intersubjetiva no trabalho. Conforme Ayres (2002, p. 15), esse movimento "permitiu trabalhar mais positiva e produtivamente os aspectos dinâmicos e relacionais do trabalho em saúde, necessários para pensá-lo não apenas como estrutura de socialidade, mas como prática social” intersubjetiva. Nesse sentido, identifica-se a articulação entre a categoria marxiana processo de trabalho e a teoria habermasiana do agir comunicativo. Mendes Gonçalves (1995, p. 22), autor que introduziu a análise do processo de trabalho na saúde coletiva brasileira, destaca dois aspectos da fecundidade teórica e prática dessa junção: a possibilidade de revalorização radical da dimensão comunicativa de quaisquer ações para promover e conduzir à emancipação, pela "elevação da argumentação racional à condição de valor inestimável enquanto força de pulsação histórica; e a sua peculiaridade em trabalhos diretamente comprometidos com a reprodução do ser humano em sua dimensão sócio-histórica”, entre os quais destaca o trabalho em saúde.

Da perspectiva habermasiana, segundo o próprio Habermas (1994, p. 30) baseado em Hegel, há três dialéticas presentes na relação entre sujeito e objeto: 
linguagem, trabalho e interação. Com base nessas, que são heterogêneas, o autor

assinala que a "interação depende das comunicações linguísticas que se tornam familiares" e que tanto a dialética da interação como a do trabalho pressupóem a mediação da linguagem. A linguagem é, enquanto utilização de símbolos representativos, substrato necessário à interação e ao trabalho. Há, assim, uma relação recíproca, de caráter dialético, entre trabalho e interação, sendo impossível subsumir um ao outro, pois possuem peculiaridades complementares, de mútua influência (PEDUZZI, 2001, 2007a, 2007b; AYRES, 2009; HABERMAS, 1994).

Segundo Habermas (1994, 2001), a interação social pode ser de natureza monológica ou dialógica. A primeira como ação baseada no sujeito que conhece, nomeia objetos e age sobre eles desde a sua perspectiva individual, não interativa. A segunda como ação fundamentada na comunicação intersubjetiva na qual conhecimento, autoconhecimento e a própria ação são frutos da interação. De acordo com o autor, há três distintas racionalidades que podem ser reconhecidas enquanto lógicas que orientam as ações: 1) a ação instrumental baseada em regras técnicas e voltada a dado êxito definido a priori; 2) a ação estratégica apoiada em regras racionais, que difere da instrumental, sobretudo porque busca exercer influência sobre as decisões do(s) interlocutor(es); 3) a ação comunicativa intersubjetiva, livre de coação interna e externa, que busca o entendimento e reconhecimento mútuo entre os sujeitos envolvidos, de modo que estes tomam em consideração uns aos outros.

$\mathrm{Na}$ ação comunicativa, os partícipes coordenam suas ações e constroem acordos pautados em um regime de validação referido a três planos: verdade proposicional, que expressa a correspondência do que é dito com a realidade, de modo que o que é dito é aceito intersubjetivamente como expressão da realidade; correção normativa, que permite aos interlocutores compartilharem o enunciado do ponto de vista ético, moral e político; e autenticidade expressiva, que faculta aos interlocutores que estabeleçam uma relação de confiança, desde que reconheçam que as opiniões, intenções, sentimentos e desejos expressos são sinceros e autênticos (HABERMAS, 2001). Assim, coloca-se um sistema formal de referência que constitui três mundos distintos, complementares e mutuamente referidos, nos quais se apóiam as pretensões de validade: mundo objetivo, mundo social e mundo subjetivo, que expressam, respectivamente, o estado das coisas, as normas sociais e a subjetividade de cada um. A ação 
comunicativa pressupõe o uso da linguagem em todas as três dimensões, articuladas pelo mundo da vida (HABERMAS, 2001).

Habermas (2001) distingue mundo da vida e sistema. O primeiro é referido a um acervo, culturalmente transmitido e linguisticamente organizado, que consiste em um horizonte comum com base no qual se entendem os sujeitos em interação. O segundo é relacionado a esferas que se constituem como autônomas por referência ao mundo da vida, orientadas por imperativos econômicos e administrativos. $\mathrm{O}$ autor reconhece, na sociedade contemporânea, um avanço da racionalidade técnica, ou do sistema e dos subsistemas, sobre o mundo da vida, ou seja, uma colonização das ações instrumentais e estratégicas em esferas da vida que deveriam ser orientadas pelo agir comunicativo.

Interessa em especial, no estudo apresentado, considerar que também no trabalho em saúde a racionalidade instrumental e estratégica invade domínios reservados à ação comunicativa, visto que há necessidades de saúde que não são reconhecidas e contempladas na atenção à saúde pela lógica técnico-científica e pelas intervenções fragmentadas de profissionais que agem isoladamente sem tomar em consideração as ações dos demais colegas. Nesse sentido, há que se considerar a consubstancialidade entre processo de trabalho e necessidades, visto que implica circularidade entre o modo de organização e distribuição e o consumo de serviços - o que configura a rede de atenção à saúde, os serviços e a atuação das equipes como "contexto instaurador de necessidades". Práticas de saúde, por um lado, reiteram necessidades e valores consagrados e, por outro, também abrem espaço à mudança e "criação de espaços de emergência de novas necessidades de saúde" (SCHRAIBER; MENDES-GONÇALVES, 2000, p. 29).

Nessa dinâmica, os profissionais e equipes podem tanto reproduzir as necessidades de saúde e os modos como os serviços se organizam para atendêlas, como buscar criar espaços de mudança para engendrar novas necessidades e correspondentes modos de organizar os serviços de saúde, o trabalho e as interaçôes, na perspectiva da integralidade e da prática interprofissional.

\section{Metodologia}

Realizou-se pesquisa qualitativa compreensivo-interpretativa. O cenário de estudo constituiu-se de todos os serviços públicos de saúde de uma região do município de São Paulo, com aproximadamente 400.000 mil habitantes, que, 
à época da pesquisa empírica, contava com 22 serviços: 14 unidades básicas de saúde (UBS), quatro serviços especializados, três hospitais e um pronto-socorro.

Desenvolveu-se, entre março a outubro de 2006, entrevista semiestruturada com 21 gerentes (diretores) dos serviços, com uma recusa em participar. As entrevistas foram gravadas e duraram em média 56 minutos. Utilizou-se roteiro com questões sobre o que é trabalho em equipe, como é a organização do trabalho no serviço, critérios de composição das equipes e instrumentos que contribuem à organização das equipes.

Utilizou-se a técnica de análise temática (BARDIN, 2009). Procedeu-se à leitura vertical dos depoimentos, em profundidade. A seguir, fez-se a leitura horizontal dos relatos, identificando-se as concepções dos gerentes sobre a organização do trabalho no respectivo serviço e os instrumentos que empregam no gerenciamento das equipes. Por fim, realizou-se análise transversal, reconhecendo semelhanças, contradiçôes e antagonismos entre os relatos (MINAYO, 2008).

A pesquisa foi aprovada pelos comitês de ética em pesquisa da Escola de Enfermagem da USP e da Secretaria Municipal de Saúde de São Paulo, e todos os sujeitos de pesquisa assinaram o termo de consentimento livre e esclarecido.

\section{Resultados e discussão}

Entre os gerentes entrevistados 12 são médicos e nove não-médicos: quatro assistentes sociais, uma cirurgiã-dentista, uma enfermeira, uma fonoaudióloga, uma terapeuta ocupacional e uma psicóloga. $\mathrm{Na}$ área de especialização, encontrou-se variedade e coerência com a atuação gerencial, 11 profissionais têm especialização relacionada à saúde pública, dos quais dez são gerentes de UBS; dois têm especialização em administração hospitalar, um é gerente de hospital e outro de um pronto-socorro; e as coordenadoras de um centro de atenção psicossocial e de um centro de convivência têm especialização em psicanálise e psicologia clínica.

A gerência de serviços de saúde pode ser apreendida, ao mesmo tempo, como instrumento do processo de trabalho em saúde e como processo de trabalho gerencial. Aqui é destacada a especificidade deste trabalho, visto que os resultados expressam concepções de gerentes centrais de serviço que se ocupam majoritariamente da gestão do trabalho. Em especial, analisam-se os instrumentos que estes afirmam lançar mão para promover o trabalho em equipe: comunicação, construção do compromisso das equipes e dos trabalhadores com o projeto 
institucional, estímulo à autonomia das equipes, definição de responsabilidades e um sistema de prestação de contas de cada equipe (accountability), promoção de mudança da cultura institucional e supervisão externa.

A comunicação foi destacada pelos gerentes, mas aparece tanto no sentido restrito de transmissão da informação, como no sentido mais abrangente de diálogo. No primeiro sentido, se expressa uma concepção monológica de comunicação, para garantir o êxito esperado das ações realizadas pelos trabalhadores e equipes, na modalidade de ação instrumental, sem considerar as vicissitudes do processo de trabalho e os eventuais debates necessários sobre os resultados a serem produzidos na atenção às necessidades de saúde dos usuários. No segundo sentido, identifica-se uma concepção de comunicação como interação social que busca o entendimento entre os sujeitos envolvidos, isto é, como ação comunicativa segundo Habermas (2001).

Se, por um lado, a comunicação é referida como o principal instrumento para a promoção do trabalho em equipe, por outro, o recurso mais utilizado para propiciá-la são as reuniōes, em diferentes modalidades, finalidades e estilos. Reunião de equipe, geral, setorial, técnica, de discussão de caso, de supervisão e do grupo gerencial ampliado.

Os gerentes referem dificuldades na realização das reuniōes: de ordem estrutural, pelos diferentes turnos de trabalho e ausência de espaço físico adequado; e relacionadas às interaçôes, tal como a pouca disponibilidade de tempo dos profissionais, em especial dos médicos, e distorções da comunicação. Há menção à necessidade de reiterar para o mesmo profissional ou mesma equipe os mesmos conteúdos, pois os trabalhadores sempre alegam desconhecimento do que foi tratado anteriormente. As reuniões não são somente espaços de troca para encontrar as melhores respostas às necessidades de saúde dos usuários e profissionais, mas também fonte de problemas e insatisfações para equipes e gerentes. De modo que não basta fazer reuniōes; é preciso promover a participação e a interação dos trabalhadores em sua dinâmica com base na argumentação crítica e fundamentada, em direção à finalidade do trabalho em saúde e dos objetivos do serviço.

As dificuldades assinaladas mostram que pode ocorrer a interrupção de uma comunicação, na qual se compartilham pretensões de validade entre os envolvidos, instalando-se desinteresse, polêmica e conflito. Frente a isso, há a alternativa de recompor-se o entendimento interrompido com base na interação 
pautada na argumentação crítica mútua. Esse é um processo dinâmico, sujeito às

vicissitudes das inter-relações, em que é desejável recompor o entendimento nos planos: objetivo, normativo e expressivo.

No gerenciamento das equipes, deve-se considerar a "postura do gerente" que, segundo os entrevistados, precisa ser coerente com o que diz e propóe. Nesse sentido, a postura deve ser de escuta e compartilhamento de decisões e não de mando. Com isso, esperam estimular a reprodução de um modelo de gestão comunicativa, conforme Rivera (2003), para o interior da dinâmica das equipes, ou mesmo a constituição de equipes com base numa atuação dialógica, de articulação e interação interprofissional. Assim, gerentes põem em pauta a autenticidade expressiva como pretensão de validade que, segundo Habermas (2001), precisa ser compartilhada no agir comunicativo. Para assegurar o entendimento entre os envolvidos, há que se validar também o plano expressivo, que revela a subjetividade de cada integrante do diálogo e põe à mostra a sinceridade do interlocutor, à medida que seus enunciados estão em conformidade com suas ações. A autenticidade expressiva recíproca tende a estabelecer relações de confiança entre os sujeitos envolvidos na prática comunicativa.

Além da comunicação, os gerentes também destacam que o mais importante na constituição de uma equipe é o profissional ter compromisso com o projeto institucional. Vale destacar que a construção desse compromisso compõe a atuação do gerente, visto que é articulador e mediador da política pública de saúde para o plano da operacionalização concreta dos processos de trabalho no cotidiano dos serviços (CAMPOS, 2000; MISHIMA et al., 1997).

Esse compromisso e envolvimento refletem a adesão crítica dos trabalhadores ao projeto, e não seu consentimento em função da influência ou da manipulação estratégica do gerente. Ou seja, da perspectiva do agir comunicativo, supóe-se que o compromisso dos profissionais com o projeto institucional tenha base no questionamento das proposições e valores que o fundamentam. Mas a adesão dos trabalhadores ao projeto institucional pode configurar-se num ambiente em que predomina a ação estratégica, seja por parte do gerente ou dos trabalhadores, em defesa de interesses próprios e de resultados que buscam produzir na condução do trabalho. Assim, na ação estratégica, os sujeitos buscam exercer influência monológica sem reciprocidade ou consideram as decisões dos demais à viabilidade de seus interesses. 
O projeto institucional é entendido como a tradução da política pública de saúde e do respectivo modelo assistencial para o trabalho em saúde, visto que este configura o modelo assistencial do serviço (MENDES-GONÇALVES; 1994; PAIM, 2002).

Importa lembrar que, embora a política pública de saúde do SUS proponha um modelo de atenção integral, o processo de trabalho em saúde tende a reproduzir a racionalidade do processo hegemônico em saúde - o modelo biomédico. Assim, há que se reconhecer, em qualquer projeto institucional, a existência de tensões entre as implementaçôes dos modelos biomédico e de atenção integral à saúde, tensões que têm diferentes configurações na atenção primária, nos serviços especializados, hospitais e pronto-socorros. Embora se reconheça que a integralidade deve nortear a rede de serviços, na atenção primária essa orientação é traço característico (CAMPOS, 2003), dada a necessidade de apreensão ampliada e contextualizada das necessidades de saúde dos usuários, de articulação das ações de promoção, prevenção e recuperação da saúde e dos diferentes saberes (MATTOS, 2004).

Portanto, o projeto institucional tem uma dada finalidade que constitui o fim a que se dirigem as atividades do trabalho cotidiano, seja a reinstauração de padrões de normatividade biomédica, seja a integralidade da saúde. $\mathrm{O}$ projeto institucional também se compõe de objetivos que, segundo Campos (2000), são distintos e configuram tensões, pois, de um lado, estão voltados às necessidades de saúde de usuários e, de outro, ligados à sobrevivência dos trabalhadores e do serviço.

Com base no modelo de cogestão, proposto por Campos (2000), e de gestão comunicativa, de Rivera (2003) e Artmann e Rivera (2006), as tensōes entre os diferentes objetivos requerem a explicitação das contradições e a construção de acordos para legitimidade do modo de se organizar o serviço e o processo de trabalho que permita contemplar os interesses dos usuários, trabalhadores e serviço. Portanto, o gerente deve construir consensos e pactuar o projeto institucional de forma comunicativa com os trabalhadores, equipes e usuários.

Os trabalhadores também precisam construir consensos em torno de um projeto assistencial comum à cada equipe. Trata-se de um plano de ação articulado ao projeto institucional voltado às necessidades de saúde dos usuários que estão sob a responsabilidade da respectiva equipe, contempladas as peculiaridades daquelas. O projeto comum de cada equipe também é elaborado 
de forma compartilhada entre seus integrantes, com base no reconhecimento intersubjetivo das pretensões de validade implícitas nos atos de fala de todos envolvidos (PEDUZZI, 2001). Entretanto, os depoimentos mostram que as equipes têm dificuldades de elaborar seu próprio projeto de trabalho com base na identificação compartilhada das necessidades de saúde e na negociação com os usuários sobre a melhor maneira de atendê-las.

A construção de um projeto com finalidade, objetivos e abordagens comuns, bem como a responsabilização da equipe, requer o reconhecimento compartilhado e contextualizado das necessidades de saúde, pois, a partir disso, a equipe juntamente aos usuários, pode definir o melhor caminho para o cuidado e a atenção à saúde. Entende-se que a definição compartilhada de forma intersubjetiva acerca da finalidade do trabalho e dos objetivos a serem atingidos ajuda a equipe a enfrentar dificuldades e problemas que emergem das dinâmicas do trabalho, visto que a equipe tem um eixo em torno do qual pode refletir sobre o cotidiano, discutir as divergências e contradições.

Gerentes também assinalam que o contexto de trabalho, em especial suas condições, dificulta a construção de compromisso das equipes e trabalhadores com o projeto institucional. A alta rotatividade de trabalhadores e a flexibilização das relações de trabalho, sobretudo pelos contratos do tipo plantão de 24 horas ou do tipo emergencial, dificultam o trabalho em equipe, que requer certa estabilidade à continuidade do projeto de trabalho e da participação dos trabalhadores. O trabalho em equipe requer que os profissionais construam uma dinâmica de trabalho com interação, articulação e objetivos compartilhados (MILLER; FREEMAN; ROSS, 2001; McCALLIN, 2001; PEDUZZI, 2001; FORTUNA et al., 2005). Nesse sentido, a gestão pública e os gerentes de cada serviço devem promover vínculo empregatício duradouro, com baixa rotatividade de pessoal e educação permanente em saúde, como instrumentos de integração das equipes. $\mathrm{O}$ fortalecimento da Política Nacional de Educação Permanente em Saúde, desenhada na Portaria GM/ MS no 1.996/07, é uma ferramenta de integração dos trabalhadores no projeto institucional e no trabalho em equipe (BRASIL, 2007).

Embora gerentes identifiquem o compromisso com o projeto institucional como uma ferramenta de promoção do trabalho em equipe, apenas parte deles problematiza o modelo assistencial. Este, em especial na perspectiva da integralidade, é tema central à construção compartilhada e intersubjetiva do projeto de trabalho 
nos serviços de saúde. Assim, os resultados da pesquisa mostram que apenas parte dos entrevistados revela uma elaboração e problematização conjunta e articulada entre trabalho em equipe e modelo de atenção integral à saúde, aspecto que justifica a própria constituição de equipes e a construção do projeto institucional (WIECHA; POLLARD, 2004; McCALLIN, 2001; PEDUZZI, 2001, 2007b; FORTUNA et al., 2005; CAMPOS; DOMITTI, 2007). Isso evidencia tanto a fragilidade da concepção dos gerentes sobre o trabalho em equipe de saúde como a limitação das ferramentas que usam no gerenciamento das equipes.

Gerentes acham que é necessário estimular e respeitar a autonomia das equipes na construção de seu projeto de trabalho, para que elas próprias resolvam seus problemas de forma comunicativa, no diálogo entre os seus componentes. A organização de serviços com base no trabalho em equipe requer que as tomadas de decisão acerca do trabalho sejam descentralizadas da gerência às equipes, com a transferência da autoridade e responsabilidade necessárias à eficácia das ações que planejam e realizam (CAMPOS; DOMITTI, 2007).

Para o enfrentamento das contradições e tensões entre o exercício da autonomia profissional e a interdependência e complementaridade objetiva dos trabalhos especializados, Campos, Domitti (2007) e Campos (2000) propõem a constituição de equipes que trabalhem com base no vínculo profissional-usuário e na adscrição de clientela. No entanto, além da interdependência entre os diferentes trabalhadores e áreas de atuação, há também a interdependência entre o projeto de trabalho de cada equipe e o projeto institucional. Assim, a ação das equipes deve ser circunscrita a um grau de autonomia que tome em consideração a necessidade de articulação e integração ao projeto de trabalho do serviço, pois ela não é independente em relação ao projeto institucional.

A análise das questôes ligadas à autonomia das equipes remete de imediato à sua responsabilização e à definição de um sistema de prestação de contas pelo trabalho executado, pois liberdade e responsabilidade são duas faces da mesma moeda, tal como a autonomia e responsabilização profissional.

A autonomia das equipes na construção do projeto comum de trabalho deve partir das necessidades de saúde dos usuários adscritos à equipe, passar pela definição da finalidade, dos objetivos e abordagens do trabalho, das atribuições e responsabilidades de cada trabalhador, até a elaboração do modo de cobrança, responsabilidade e prestação de contas em relação aos resultados. Esse conjunto 
de momentos do trabalho produzido pela equipe é que permite configurar um projeto comum respaldado pela prática comunicativa.

A responsabilização de cada profissional perante os usuários e os demais membros da equipe e a prática de prestação de contas estão relacionadas com a possibilidade de controle do processo de trabalho. Ou seja, os mecanismos de responsabilização e prestação de contas também precisam ser definidos de forma compartilhada e comunicativa, entre a gerência e os trabalhadores e equipes, na busca da construção de consensos que, embora provisórios a determinados recortes de tempo e condiçôes de trabalho, expressem algum grau de entendimento entre os envolvidos em relação ao trabalho produzido, e não a mera fiscalização de ações (RIVERA, 2003).

A mudança da cultura institucional também é apontada por gerentes como instrumento para promover o trabalho em equipe, visto que tem um papel importante na configuração da dinâmica de trabalho do serviço, ao expressar valores, crenças, tradições e pré-interpretações de que os profissionais lançam mão para refletir, interpretar e intervir nas situações cotidianas de trabalho. No entanto, também a esfera dos valores vigentes nas práticas de saúde deve ser questionada, para que se possam fazer mudanças nos processos de trabalho e na gestão do serviço (PEDUZZI, 2007a, 2007b; PINHEIRO; BARROS; MATTOS, 2007; RIVERA, 2003).

Os valores compartilhados na cultura institucional que prevalece nos serviços de saúde ainda são a fragmentação, as relações hierárquicas de trabalho, a atuação profissional individualizada e o paroxismo instrumental da racionalidade técnico-científica. Contudo, outros valores e paradigmas presentes no contexto contemporâneo, nacional e internacional, orientados por um horizonte normativo diferente, mesmo num cenário de intensas disputas e tensões, destacam valores como: integração, democratização institucional, horizontalização das relações trabalho, trabalho em equipe e integralidade da saúde (PEDUZZI, 2007a, 2007b).

Isso evidencia que as mudanças precisam ser feitas a partir do reconhecimento dos valores vigentes, da argumentação crítica e intersubjetiva a seu respeito e também, como aponta Rivera (2003), da identificação dos valores-chave da cultura do respectivo serviço, em que se percebam traços positivos que podem ser funcionais à mudança na direção almejada. Nesse sentido, Ayres (2005) analisa que as tecnociências biomédicas são orientadas por um horizonte normativo restrito 
e restritivo em relação ao que se quer entender hoje por saúde, uma concepção ampliada que contempla suas múltiplas dimensões de forma contextualizada - a integralidade da saúde. Contudo, são essas mesmas tecnociências que constroem as bases das práticas de saúde dominantes, em relação às quais se podem construir outros horizontes, pautados em outros valores e práticas. Trata-se, assim, de mudança da cultura institucional e, simultaneamente, da racionalidade que orienta os processos de trabalho, os projetos assistenciais das equipes e o projeto institucional, pois todos esses âmbitos expressam a dimensão interativa e tecnológica das práticas de saúde.

Por fim, gerentes fazem referência à supervisão externa como instrumento de promoção do trabalho em equipe, para suporte e apoio frente ao sofrimento que o trabalho em saúde pode acarretar aos trabalhadores e às equipes ou para que a equipe reconheça a dinâmica do grupo, bem como suas possibilidades e limites no trabalho compartilhado. Ou seja, em determinadas situações de trabalho, o gerente e as equipes, de forma compartilhada, reconhecem os limites internos - no próprio serviço ou nas equipes - das possibilidades de compreensão e intervenção na dinâmica de trabalho e, de comum acordo, podem optar pela supervisão externa.

As abordagens da análise institucional e da escola argentina de grupos, em especial do grupo operativo de Pichon-Rivière, fundamentam e permitem o reconhecimento e manejo da dinâmica das instituições, grupos e equipes, constituindo uma vertente relevante à supervisão externa (FORTUNA et al., 2005; MATUMOTO et al., 2005). Entre as gerentes, há quem trabalhe com a análise institucional e use esse recurso na gerência, embora durante alguns anos a equipe tenha recorrido também à supervisão externa, financiada pelo próprio grupo de profissionais.

Segundo Matumoto et al. (2005), na ótica do movimento institucionalista, a supervisão é abordada por um conjunto de escolas e tendências diferentes, mas todas visam a propiciar processos de autoanálise e de autogestão dos sujeitos que participam. A autoanálise é entendida como a capacidade que os coletivos têm de se tornarem protagonistas nos processos em que estão envolvidos e a autogestão como a capacidade de auto-organização dos coletivos para atingirem seus objetivos. Assim, as autoras destacam que a supervisão externa "tem o propósito de facilitar que as equipes de saúde analisem seu modo de se relacionar no trabalho, de produzir 
ações, quer na direção da produção de procedimentos, quer na de cuidados, ou seja, que se analisem como equipes" (MATUMOTO et al., 2005, p. 16).

\section{Considerações finais}

Os resultados deste estudo confirmam a comunicação entre os profissionais e destes com os usuários como condição sine que non do trabalho em equipe de saúde. Também os demais instrumentos referidos são ligados à comunicação. Esta, para os diretores de serviços com relatos mais consistentes e fundamentados sobre o tema de estudo, é entendida como trocas e conversas que buscam o entendimento entre os sujeitos envolvidos para a construção de consensos, acordos e pactos de trabalho. Assim, a comunicação, como interação pautada na argumentação intersubjetiva, quando aplicada à construção de equipes integradas está orientada para o trabalho, isto é, à eficácia e efetividade da atenção às necessidades de saúde dos usuários.

O trabalho em equipe como ferramenta do processo de trabalho em saúde requer, do gerente, a composição de um conjunto de instrumentos - construir e consolidar espaços de troca entre os profissionais, estimular os vínculos profissional-usuário e usuário-serviço, estimular a autonomia das equipes, em particular à construção de seus próprios projetos de trabalho, e promover o envolvimento e o compromisso de cada equipe e da rede de equipes com o projeto institucional. Esta prática remete à gestão comunicativa e cogestão.

Contudo, a pesquisa também aponta para outro conjunto de gerentes que, embora minoritário no estudo, apresenta uma concepção restrita de comunicação, como mera troca de informação, e um relato frágil sobre gerenciamento de equipes. Deste modo, a pesquisa evidencia o desafio de ampliar o entendimento dos gerentes acerca do trabalho em equipe, na perspectiva comunicativa, para a consolidação da prática interprofissional em saúde.

\section{Referências}

ALMEIDA M. C. P.; MISHIMA S. M.; PEDUZZI M. A pesquisa em enfermagem fundamentada no processo de trabalho: em busca da compreensão e qualificação da prática de enfermagem. In: CONGRESSO BRASILEIRO DE ENFERMAGEM, 51., Congresso Panamericano de Enfermeria, 10., 1999, Florianópolis. Anais...Florianópolis: ABEn; 1999. p. 259-277.

ARTMANN E.; RIVERA F.J.U. Humanização no atendimento em saúde e gestão comunicativa. In: DESLANDES S. F. (Org.). Humanização dos cuidados em saúde: conceitos, dilemas e práticas. Rio de Janeiro: Fiocruz, 2006. p. 205-231. 
AYRES J.R.C.M. Do processo de trabalho em saúde à dialógica do cuidado: repensando conceitos e práticas em saúde coletiva. 2002. 179p. Tese (Livre-docência em Saúde Coletiva) - Faculdade de Medicina, Universidade de São Paulo, São Paulo, 2002.

Hermenêutica e humanização das práticas de saúde. Cienc Saude Colet., Rio de Janeiro, v. 10, n. 3, p. 549-560, 2005.

. Cuidado: trabalho e interação nas práticas de saúde. Rio de Janeiro: Cepesc, 2009. 284p.

BARDIN L. Análise de conteúdo. Lisboa: Ediçōes 70, 2009. 281p.

BRASIL. Portaria GM/MS n 1996, de 20 de agosto de 2007. Dispõe sobre as diretrizes para a implementação da Política Nacional de Educação Permanente em Saúde e dá outras providências. Diário Oficial da Uniāo, Brasília, DF, n 162, ago. 2007. Seção 1.

CAMPOS G.W.S.; DOMITTI, A. C. Apoio matricial e equipe de referência: uma metodologia para gestão do trabalho interdisciplinar em saúde. Cad Saúde Pública, Rio de Janeiro, v. 23, n. 2, p. 399-407, 2007.

CAMPOS G.W.S. Um método para análise e co-gestão de coletivos. São Paulo: Hucitec, 2000. 236p.

. Saúde Paideia. São Paulo: Hucitec, 2003. 192p.

FORTUNA, C. M. et al. O trabalho de equipe no Programa de Saúde da Família: reflexôes a partir de conceitos do processo grupal e de grupos operativos. Rev Lat Am Enfermagem, Ribeirão Preto, v. 13, n. 2, p. 262-268, 2005.

FORTUNA, C.M. O trabalho de equipe numa unidade básica de saúde: produzindo e reproduzindo-se em subjetividades - em busca do desejo, do devir e de singularidades. 1999. 247 p. Dissertação (Mestrado em Enfermagem em Saúde Pública) - Escola de Enfermagem de Ribeirão Preto, Universidade de São Paulo, Ribeirão Preto, 1999.

HABERMAS, J. Técnica e ciência como ideologia. Lisboa: Edições 70, 1994. 152p.

. Teoria de la acción comunicativa. I: Racionalidad de la acción y racionalización social. Madrid: Taurus, 2001. 517p.

MATTOS R. A. A integralidade na prática (ou sobre a prática da integralidade). Cad Saúde Pública. Rio de Janeiro, v. 20, n. 5, p. 1411-1416, 2004.

MATUMOTO S. et al. Supervisão de equipes no programa de saúde da família: reflexões acerca do desafio da produção de cuidados. Interface Comum. saúde educ. Botucatu, v. 9, n. 16, p. 9-24, 2005.

Mc CALLIN A. M. Interdisciplinary practice - a matter of teamwork: an integrated literature review. J Clin Nurs. England, v. 10, n. 4, p. 419-428, 2001.

MENDES-GONÇALVES R. B. Tecnologia e organização social das práticas de saúde. São Paulo: Hucitec, 1994. 278p. 
Seres humanos e práticas de saúde: comentários sobre "razão e planejamento". In:

GALLO, E. (Org.). Razão e planejamento: reflexões sobre política, estratégia e liberdade. São Paulo: Hucitec, 1995. p. 13-31.

MILLER C., FREEMAN M., ROSS N. Interprofessional practice in health and social care: challenging the shared learning agenda. London: Arnold, 2001. 248p.

MINAYO M. C. S. O desafio do conhecimento. Pesquisa qualitativa em saúde. $11^{a}$ ed. São Paulo: Hucitec, 2008. 407p.

MISHIMA S. M. et al. Organização do processo gerencial no trabalho em saúde pública. In: ALMEIDA M. C. P., ROCHA S. M., (Org.). O trabalho de enfermagem. São Paulo: Cortez, 1997. p. 251-296.

PAIM J. S. Saúde: política e reforma sanitária. Salvador: Instituto de Saúde Coletiva/ Centro de Estudo e Projeto em Saúde, 2002. 447 p.

PEDUZZI M. Equipe multiprofissional de saúde: conceito e tipologia. Rev Saúde Pública, São Paulo, v. 35, n. 1, p. 103-109, 2001.

. Trabalho em equipe de saúde no horizonte normativo da integralidade, do cuidado e da democratização das relações de trabalho. In: PINHEIRO R., BARROS M. E. B., MATTOS R. A. (Org.). Trabalho em equipe sob o eixo da integralidade: valores, saberes e práticas. Rio de Janeiro: IMS/UERJ: CEPESC: ABRASCO, 2007a. p. 161-177.

. Trabalho em equipe de saúde da perspectiva de gerentes de serviços de saúde: possibilidades da prática comunicativa orientada pelas necessidades de saúde dos usuários e da população. 2007. 247p. Tese (Livre-docência em Enfermagem) - Escola de Enfermagem, Universidade de São Paulo, São Paulo, 2007b.

PINHEIRO R., BARROS M. E. B., MATTOS R. A. Trabalho em equipe sob o eixo da integralidade: valores, saberes e práticas. Rio de Janeiro: IMS/UERJ: CEPESC: ABRASCO, 2007. 207 p.

RETCHIN S. M. A conceptual framework for interprofessional and co-managed care. Acad Med, Pittsburgh, v. 83, n. 10, p. 929-933, 2008.

RIVERA F. J. U. Análise estratégica em saúde e gestão pela escuta. Rio de Janeiro: Fiocruz, 2003. 310 p.

SCHRAIBER L. B. et al. Planejamento, gestão e avaliação em saúde: identificando problemas. Cienc Saúde Colet. Rio de Janeiro, v. 4, n. 2, p. 221-242, 1999.

SCHRAIBER L. B., MENDES-GONÇALVES R. B. Necessidades de saúde e atenção primária. In: SCHRAIBER L. B., NEMES M. I. B., MENDES-GONÇALVES R.B. (Org.). Saúde do adulto: Programas e ações na unidade básica. 2a ed. São Paulo: Hucitec, 2000. p. 29-47.

WIECHA J., POLLARD T. The interdisciplinary e health team: chronic care for the future. J Med Internet Res. Toronto, v. 6, n. 3, e22, 2004. 
Team work under the perspective of health services management: instruments for the construction of inter-professional practice Study on the contribution of the managerial action for the promotion of inter-professional practice. It is a qualitative research carried out in 21 public health services facilities in a region of São Paulo, using data from semi-structured interview with 21 managers (directors) and the technique of theme analysis was used. As a result, in order to promote team work, managers use tools such as: communication, construction of commitment on the part of teams and workers in relation to the institutional project, stimulus to team autonomy, definition of responsibilities and accountability, promotion of institutional culture change and external supervision. The conclusion is that the tool of communication and others, whenever applied to the promotion of team work, are work-oriented, that is, oriented to efficient and effective care to the health needs of the users.

> Key words: patient care team; management; work. 